\title{
Compatible cultural configuration: One secret of international project management
}

\author{
Bhattarai, Raj Kumar $₫$ \\ Tribhuvan University, Nepal (raj.bhattarai@outlook.com)
}

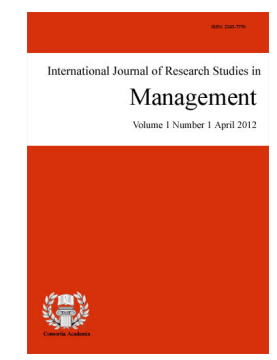

Accepted: 1 May 2016

ISSN: 2243-7770 Online ISSN: 2243-7789

OPEN ACCESS

\section{Abstract}

Six decades long planned economy of Nepal passed through a large number of socio-economic development projects, which heavily relied on financial and technical assistance of advanced countries and international organizations. However, the outcomes of the development projects could not address the primary concern of the people, and eventually the entire efforts of development resulted in political insurgency, economic turmoil, and chaos in the country. One of the main reasons behind the scenario was incompatibility between the development project specifications and the socio-cultural configuration in the country. This study reviewed the attempts of six decades of developmental project management perspectives. An assessment of the execution pattern of the projects provided insight about the services composition in the projects at one part, and an effort of identifying social processes, events and festivals helped to describe the cultural configuration and value system of the society at the other part. An analysis of the project specifications indicated a wide incompatibility in composition of the services in relation to the projects. The value system, cultural configuration, and outcomes of the projects indicated a high level of importance of compatibility between project specification and cultural configuration. This paper concludes with determination and description of cultural configuration and services composition that are taken as an integral part of international project management.

Keywords: Nepal; cultural configuration; social value; project management; services alignment 


\section{Compatible cultural configuration: One secret of international project management}

\section{Introduction}

There were five major political system changes in the course of the last fifty years' development efforts of Nepal. In the year 1951, the Rana regime of about 103 years old came to its end. During the years 1960-61, party less Panchayat system replaced the newly introduced multiparty system. A major trial took place in the year 1979-1980, which resulted in favor of the existing party less political system. People's movement took place during the years 1989-1990 and replaced the multiparty system. Nepal Communist Party (Maoist) initiated political movement just after five years of the restoration of multiparty system in against the monarchy, and ultimately, the other major political parties also joined the movement and the country declared a federal republic on the $28^{\text {th }}$ day of May 2008 after abolishing the 'monarchy' of about 240 years old. About a decade later, the country found a constitution in the year 2015. Political unrest remained continuous even after promulgation of the constitution.

\subsection{Problem statement}

Socio-cultural dimension was noticed widely being ignored in the change and development interventions of Nepal. Incompatible ad-hoc decisions and actions taken in the past could not meet the aspirations of Nepalese people (Acharya \& Bhattarai, 2012). Furthermore, the changes in political system did not address the geo-socio-economic issues. The planned economy continued without paying appropriate attention to the service sectors, which were one viable alternative for the prosperity of Nepalese society. The efforts made to promote manufacturing sectors remained unsuccessful. The service culture of Nepali people could have been developed and utilized nationally and internationally, but it was ignored and could not be materialized in the past days. It has been argued that development projects should address socio-cultural concerns first; therefore, primary attention to the cultural compatibility is a must while writing and meeting the project specifications.

In the context of global economy, bilateral and multilateral developmental projects are exposing to a great challenge worldwide. They are realizing an urgent need to prepare their executives for a global business environment, which demands living and working in different cultural settings. This environment demands a broader range of skills and capabilities to interact effectively with people from different cultural backgrounds who differ dramatically in terms of language, costumes, and lifestyles (Chong \& Park, 2003). Moreover, knowledge management, technology transfer, and intellectual property rights become ineffective without service management.

Research in international project management has not paid appropriate attention to the cultural diversity that exists in the countries like Nepal. The internationalization of project management practices based on the particular western environment cannot serve best in the rest of the world, but try to impose the western values over the rest of the world. Almost all the development projects based on western models found failed in Nepal in one way or the other (Bhattarai, 2006). Today, internationalization of project management practices has been unavoidable and model-based project management attempts are being ineffective.

People's value system varies across societies and it does not permit model-based development practices and interventions. Value differs across the culture like- Japanese may value 'work' and Westerners may value 'worth', but what Nepalese people do value has been an important question to be answered. Moreover, what do people 'value' across the societies, and how to determine the appropriateness of services for the people, are two critical questions in international project management practices. 


\subsection{Objectives}

The major thrust of this paper is to advocate for a model-free development project management practices by giving emphasis on compatible cultural configuration. The specific objectives of this study are:

$>\quad$ To identify the dimensions of cultural configuration;

$>\quad$ To assess the value system of people in society; and

$>\quad$ To propose a model-free practice of services composition in international project management.

\subsection{Method}

This study carried out comprehensive inquiries on cultural diversity and socio-economic history of Nepal. One hundred and twenty eight semi-structured interviews with people of different status completed at different place and time across the country. Travel notes of the author of visiting different parts of the country were extensively used in addition to the literature reviews and individual interviews. Conversations with leaders in different areas like religion, politics, project management, and business were made at different point of time for the purpose of cross verification, and notes on such conversations were prepared for further analysis and interpretation. The author's experience of more than two decades working with different national and international project management had been used in respondent selection and following conversation with them.

The information obtained from various verbal and non-verbal sources arranged in categories. A detailed description, specification, procedure, and method of the cultural elements were prepared for understanding 'value' of the people in pluralistic social settings. The author's experience, intuitive reasoning, and judgment became instrumental in understanding the cultural configuration and its interpretation. Model-free practices for service alignment with development project specifications have been proposed for international project management in developing countries.

\subsection{Limitation}

The services have been grouped into three categories as person-driven, product-driven, and process-driven services. Emphasis has been given to the person-driven services. The descriptions, specifications, and procedures in relation to the dimension of the cultural configuration have been derived from one country perspective. The detail analysis, interpretation, and consideration of standardization, customization, and personalization of the model-free practices have also been excluded in the paper. The local terms that were not accurately translated into English are mentioned on their own.

\section{Cultural Configuration}

Origin of the culture was relating to the mythological epoch of Vedic, Ramanayana and Mahabharata. During the epochs, people were more concerned about their death and they were very serious to secure a good place (heaven) after their death. They did not give more emphasis on the collection for the future generation, but wanted to go to heaven after their death by doing the best work throughout their lives.

At the beginning, there were two types of life styles. One was the life style of Rishi-Munis, who were pure vegetarians and philosophical thinkers living in forest, and others were involved in basic agricultural activities. What was right or wrong and good or bad had been explained verbally by the Rishi-Munis, which ultimately shaped the value system of the society.

Culture was the basic assumptions and beliefs that were shared by the members of a society. It has covered the taken-for-granted ways of doing things including rituals and traditions. E. Schein defined organization culture as the basic assumptions and beliefs that are shared by members of an organization that operate 
unconsciously and define in a basic taken-for-granted fashion an organization's view of itself and its environment (Johnson, Scholes, \& Whittington, 2009). Culture was a property of an individual or a society and considered as a manmade weapon that has been shaped and reshaped by the frequency of practices over time. It was an outcome of the process of change and development as well.

This study argued that project management team is considered as a unique set of culture that is shared by its members, and the project specifications must be formulated in congruence with the shared value. Therefore, there is interaction between the project organization's culture and project individual's culture. Some projects develop a strong culture, and the new entrant are acting and interacting with it, but the entrants are feeling both- compatible and incompatible. When the individual becomes compatible with the project organization's culture, s/he continues with it, otherwise s/he resists or leaves the project, and tries to join another one that best fits with his/her culture. For instance, it has been found that an accountant left a bridge construction project and joined similar other project, and did exactly same job of accounting for similar compensation and benefits. That is why 'person job fit' is less desired than the 'person culture fit', more especially, in service sectors (Bhattarai, 2015).

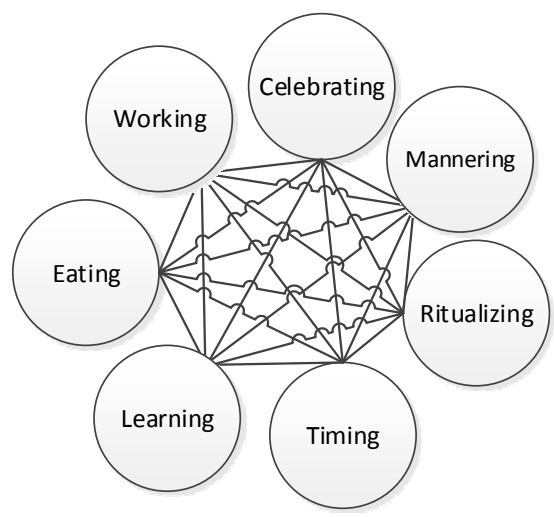

Figure 1. Cultural configuration

Now a question comes- can organizations create culture and export it to different projects of international nature? During the past, the regional /national culture was considered most important; however, today it is time to think on individual culture while providing services. Preference and choices of individual is one major determinant in service sectors. During the visit of different places for the purpose of this study, it was found that a substantial differences, at the same place and time, in choices and preferences among the family members while meeting the requirement of their own religious rituals. Similarly, choice and preference differences were noticed within different rituals of different caste at different parts of the country. Eventually, individual preferences and choices were playing decisive roles while meeting the norms of the rituals.

The foods and taste termed as eating, events and festivals termed as celebrating, pattern and styles of rituals term as ritualizing, business and social etiquettes termed as mannering, items and pattern of tasks and activities are termed as working, patterns of change and acceptance to the change termed as learning, and significance given to time and situation termed as timing while determining the 'cultural configuration'. The variation in the dimension of the configuration and the degree of individual's adaptability to the variation were made the basis for determining the service design of standardization, customization, and personalization.

\subsection{Mannering}

Mannering dimension of culture was concerned to the etiquette that served as an instrument while dealing with others. It referred the formal rules of correct or polite behavior in society or among the members of a particular profession. The etiquette listing herewith is based on the conversations and consultations with the individuals of different status at different locations in addition to the field notes and experience of the author. Different etiquettes found in different communities of Nepalese society and more interestingly, varying from persons to persons. The followings are some of the reflections of the important etiquettes that were playing significant roles in business dealings as well.

Choice of attire (business; funeral; wedding; parties and celebrations; meetings; visiting relatives and high ranking officials; dining; being at home, office, events and festivals) 


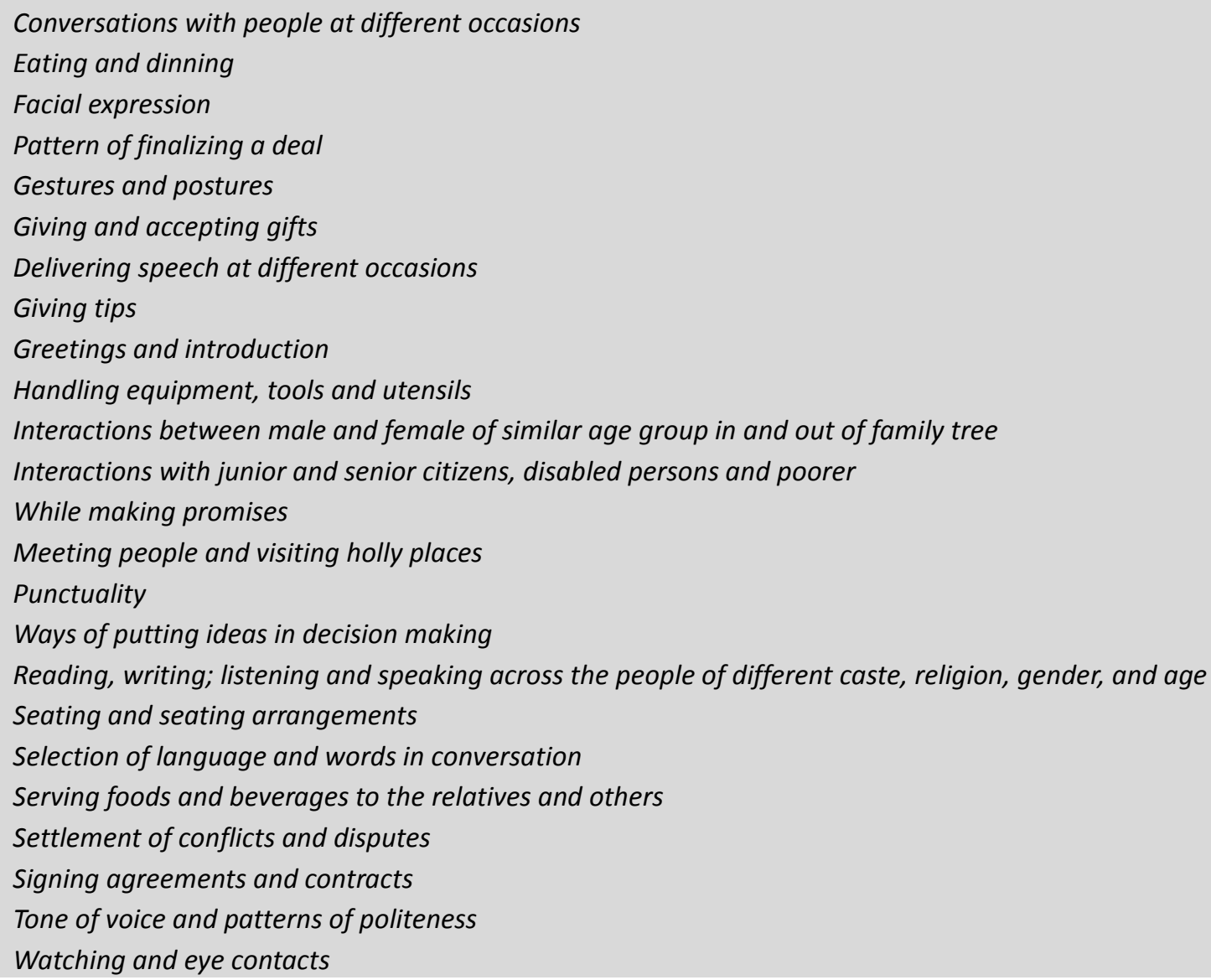

\subsection{Learning}

It is argued that change is inevitable; therefore, learning becomes a natural phenomenon. The answer to the question- how do people learn the ways of doing or making things and keeping others happy and prosperous -was a major thrust of understanding the learning dimension of a culture. In due course of making lives more comfortable and convenient learning become a major driver of a society where the formal and informal ways of learning were in practices.

In most of the areas of the country, daughters were asked to learn cooking, decorating, and beautification at their home informally from the elder citizens of the family especially from her mother/grandmother. The daughter was going to join another family after marriage, so people assumed that they need to know more about it. They were learning how to serve others and keep them satisfied at their own home or family. The works were divided among the caste, gender, and age accordingly and one had to acquire that knowledge and skills which help to continue their traditional profession. Moreover, people had learned to make their lives environment friendly. Some of the aspects of learning culture are as mentioned below.

Learning from mother, father and family members

Son gets special advices from his father/grandfather; and daughter gets from her mother/grandmother Boys and girls gain sexual education themselves or learn secretly from friends and peers or from Internet and movies

Daughter receives special advices on her wedding day from her mother/grandmother just before leaving for her bridegroom's home.

Learning effectiveness is based on the teacher-students relationships

Definition of paap (sins) and dharma (good act for others)

Belief in reincarnation 
Emphasis on son's education than the daughter's education (existing in some communities)

Learning of culture, moral codes and ethical standards in their family informally

People intend to acquire knowledge and skills that help them to continue their traditional profession or

family business

Certain communities like Raaute do not consider school and college education as essential

What people already know is most important than what is right and appropriate to them; what is

available is more important than what is appropriate and suitable to them

Family, friends, and peers are considered most effective sources of learning

Girls or daughters are asked to learn how to prepare and serve different varieties at different occasions;

however, sons are asked to learn how to continue their traditional profession/family business or initiate a

new one.

Knowledge and skills are transferred orally; apprenticeship is widely used in transfer of knowledge and

skills

Widely availability of formal education

No documentation of informal education

One of the most important learnings of people in the last couple of years was the tolerance for all the hardships. They had learned to accept the events and incidents like power cut of 16 hours and more every day, shortage of commodities in the market, skyrocketing price of goods and services, frequent strikes and lockouts, unpredictability, and insecurity of person and property. The hardships had made cultural immune system stronger than before. However, Hinduism has taught them, 'do your duty, do not expect for its return, because the return is not at your hand'. This might be one reason that the people were found less serious about the consequences of their work and hardships.

\subsection{Working}

The caste system was influencing the ways of getting things done with and through others in the society. The society was consisting majority of Hindus who comprised Brahmins, Kshatriyas, Vaishyas and Shudras. A Brahmin was typically engaged in academic and advisory activities; a Kshatriya was involved in ruling and safeguarding the society; a Vaishya was engaged in agriculture and business; and Shudras (Bhalla, 2005) were traditionally smiths, technicians, and helpers. The Brahmin was considered the upper caste and the Shudra the lower one. The society was considered ideal when each of its members maintains the values, disciplines, and norms of its own.

Tendency of people towards the construction of Paati Pauwa, water taps, Chautaaro, and plantation of Bar Pippal over the Chautaaro in memory of deceased relatives was one unique example in the area of services sectors in Nepal. The purpose of such tasks was purely for service to the others free of charge, and it had no commercial value at all. The coming generation maintains such things and keeps updated and useful.

The people loved feeding and accommodating the guests free of cost. People considered Atithi (guests) as God and felt pleasure by providing them with varieties of food items and services. Moreover, they were worshipping animals, trees, rivers, lakes, mountains, peaks, and so on to honor their importance in people's different part of lives.

An interesting thing was Sinicism, which was considered as an important profession, especially in rural areas of the country. Jyotishi (traditional astrologist) was another equally important profession in the society. There were teachers of religious rites and rituals usually known as Puret in Brahmin community. In the same line, female prostitution was found traditional profession of Baadi community especially in a Western part of the country. The culture permitted such prostitution and the husband was also found reasonably satisfied with the profession of his wife!

Most of the people were found engaged in their traditional profession, mostly in agriculture. Traditional 
engagement of people was seen especially in guiding tourists, religious rites and rituals; mountaineering and trekking; handicraft and metal craft; carpentry; masonry; repair and maintenance; painting; knitting, weaving and tailoring works. Some of the dimensions of working aspect of the culture were as mentioned hereunder.

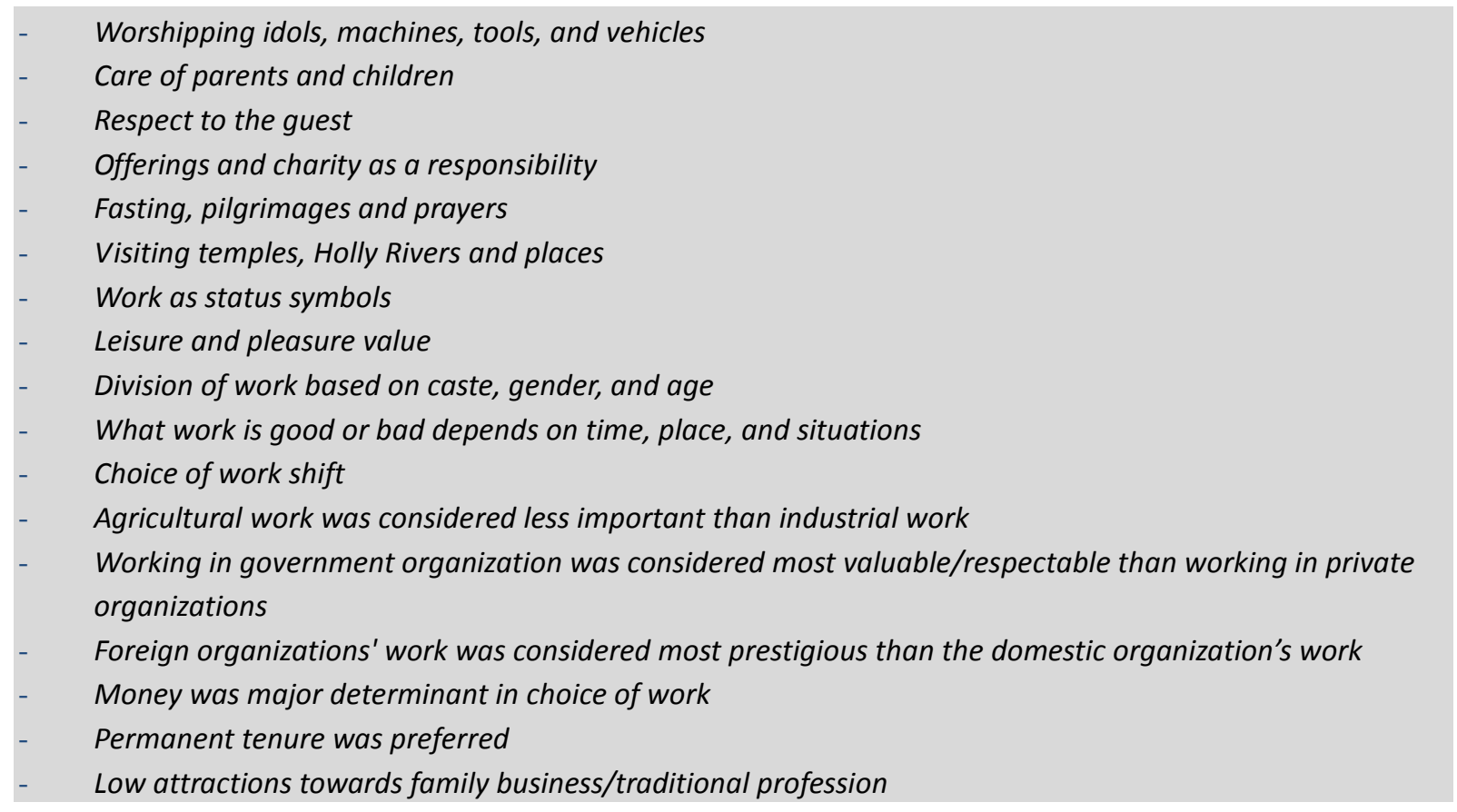

\subsection{Eating}

Eating dimension of a culture varied according to caste. There was a strong relationship between the food items and caste. The people were preparing foods and beverages for them at their own home. Occasionally, families were going to hotels and restaurants in special condition or occasion. Brahmin's varieties of food items and other cast's food items were found different, specifically at their homes. Varieties in different communities/caste, and different taste even within the varieties, was very common. Foods items were selected mostly from the perspective of taste and caste than the biological or physical requirement. Common items were prepared for all the family members except some exceptions. Some of the aspects of foods and taste have been mentioned as hereunder.

Eat and drink as much as you can, and enjoy the events and festivals

Foods and taste varieties differ across caste, religion, status, and positions

Most of the events and festivals demand special dishes and items

Restrictions on items of food and beverage depending on the caste and religions

Various cultural taboos over foods and beverages

Taste and composition of foods and beverage items based on weather, seasons, and geographic locations

Timing food items and eating them

Work and occasion specific food items

Foods and beverages preparation convention

Dining at home and out

Status symbols of eating

Common menu in family meal

\subsection{Ritualizing}

Ritualizing part of a culture was concerned to the tradition, convention, social norms and rituals that were 
reflected in a series of actions mostly carried out in the same way over time especially as part of a cultural ceremony. A large number of rituals were found in the society, specifically among Hindus. Some of the important and widely carried out were as mentioned hereunder.

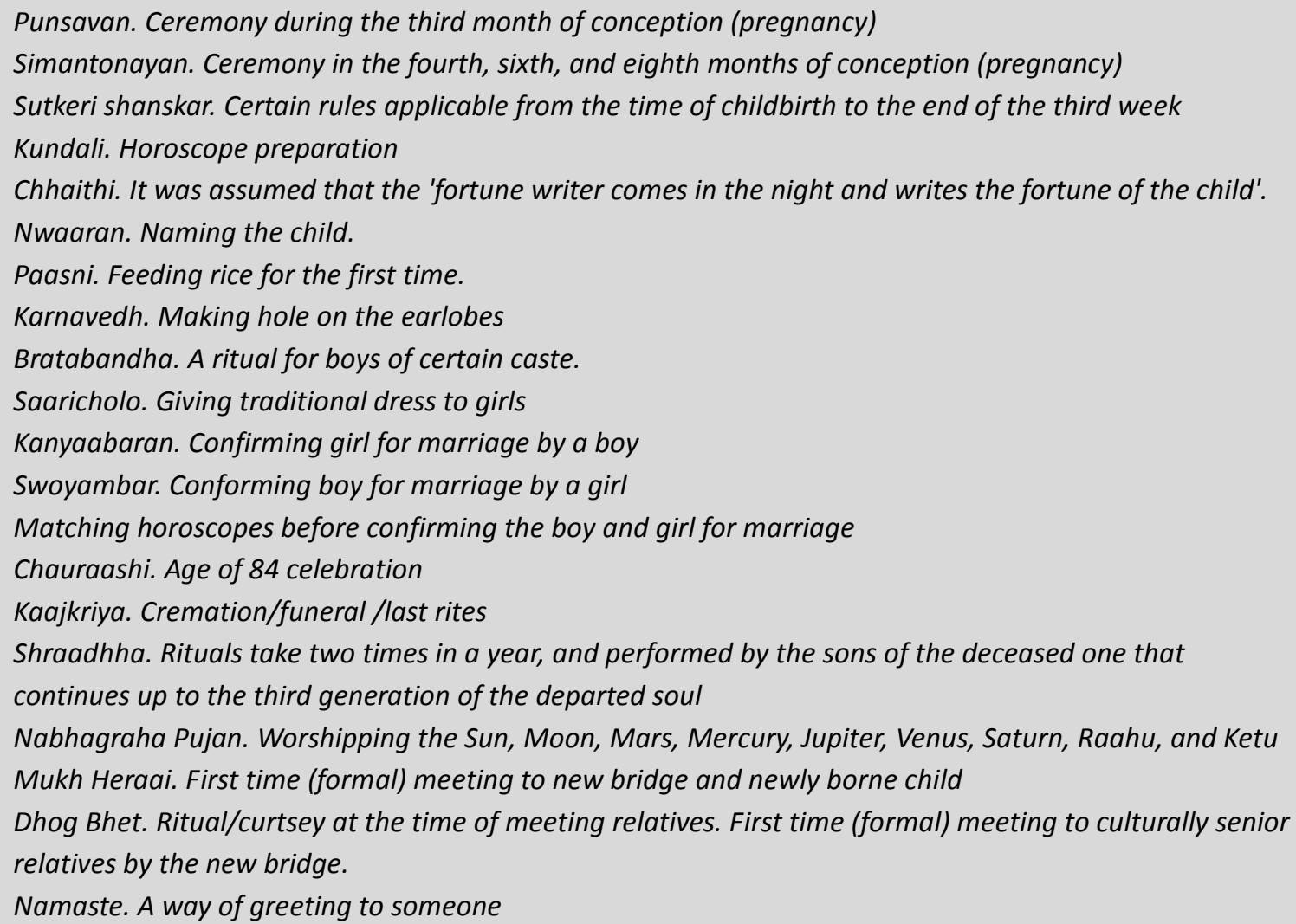

\subsection{Celebrating}

Celebrating part of the culture referred to the events and festivals taking place in the society. There were 341 different events including 173 festivals in the society. Majority of people were involved in and committed to celebrate different events and festivals. Organizational work schedule and business activities were found deeply associated with the events and festivals. The local authority and the government were granting public holidays in some of the cases nationally, regionally, and locally depending on the nature of the events and festivals.

Public holidays in Nepal were found as- national festivals 23 days; regional festivals 9 days; special day holidays 7 days; holidays for women 3 days; and holidays for educational institutions, civil servants, and disabled persons one day each. The holidays excluded the weekends and locally declared holidays. There could be additional holidays depending on the situation as well.

\subsection{Timing}

Timing dimension of a culture was concerned with the significance given by the people in relation to their action and reactions. It was also known as muhurta, which was a time of doing or making things usually calculated on the basis lunar calendar. Two types of calendars were mostly used in the society- one was solar and the other was lunar. The solar calendar was used for calculation of days and the lunar for tithi. The muhurta; rituals; events and festivals were taking place by following the tithi.

The events and rituals follow certain times and occasions. One cannot ignore the time and tries to be most punctual. One important aspect in Hinduism was that the tasks couldnot be performed only on the intention of the parties, but the planetary positions and tithi in relation to the desired rites or rituals play decisive role in 
determining the events. The parties can only select the appropriate time from among the available time slots. The interpretation of different events, incidents, and work were based on the time derived as such. Time of birth and death both are considered more important and less important respectively among others. Timing in meeting the elements of cultural configuration was considered of higher significance. The best and worst times were calculated and the best one was selected for each of the case, action, and activity. The following are some of the events and activities that were strictly requiring muhurta in the society.

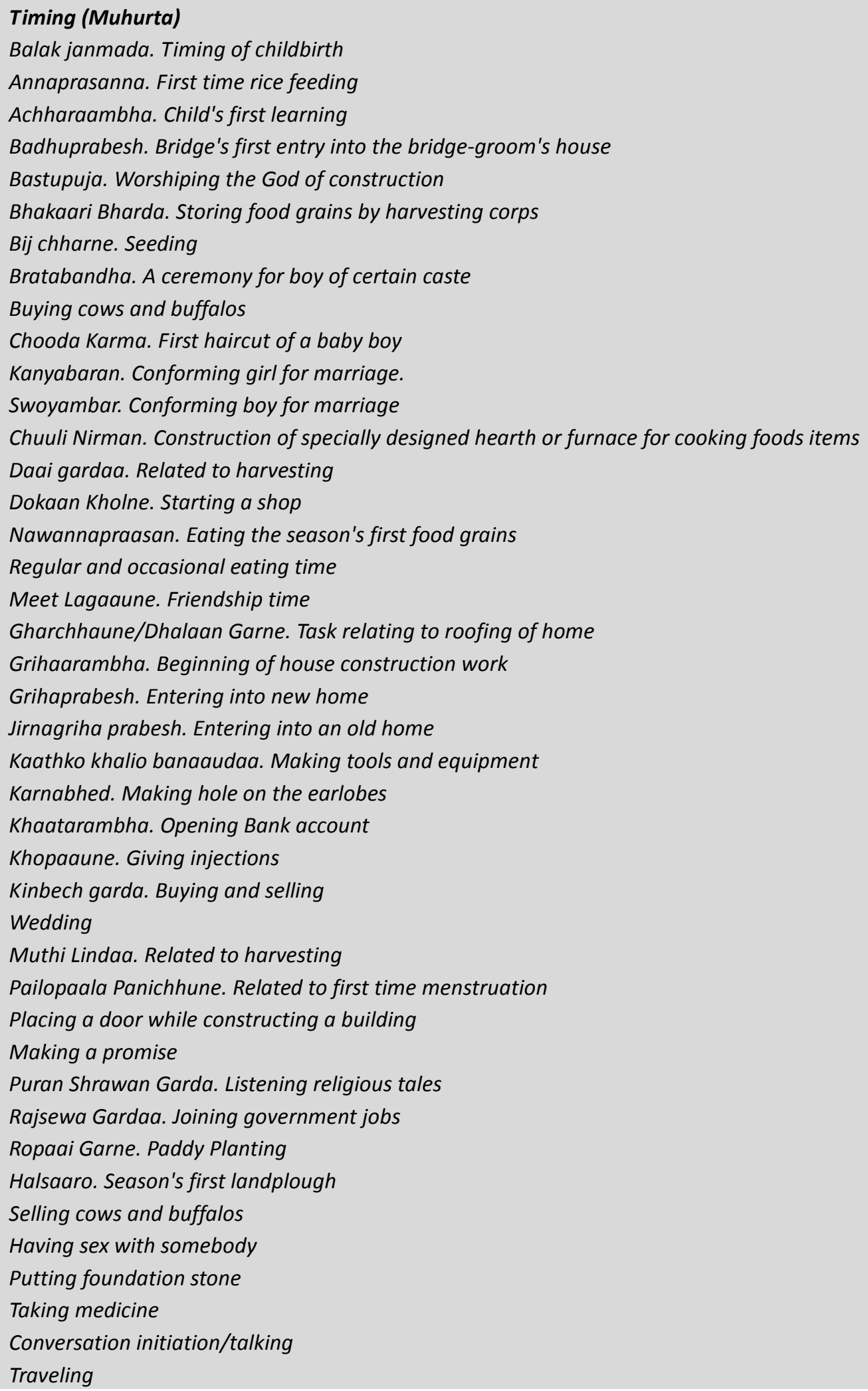


Bhattarai, R. K.

\section{Sleeping and wake-up}

Working

Singing and dancing

\section{Discussion}

International project management practices cannot be separated from the technology transfer, intellectual property, and knowledge management. One dimension of project management is the flow of funds, commodity, and technical personnel from developed countries to the developing and underdeveloped countries. The service management is inseparable from such flows that are flowing in different forms. For instance, the donation and assistance come along with certain conditions like procurement, consultancy, facilities, and insurance. The quality and service specifications were usually above the national standards of the developing countries with significant variations. There was no proper accounting and recording of the real amount of service and its type because of its elusive and invisible nature.

One cannot develop culture in a laboratory and out as a commodity. Frequency of practices of an individual or group or a society lays foundation to understand the culture. What a person does in a particular situation at different point of time that helps us to understand what he actually values. Understanding the beliefs, attitudes and value of people help to determine the cultural diversity and that help shape the individual's ethics. Ethic is a moral judgment about what is right or wrong, and good or bad. The judgment of an individual is influenced by his or her value. Both the cultural environment and functional factors (those unique to the individual) have an impact on the growth of beliefs. Beliefs in due course of an individual's life and profession affect his decisions. Therefore, how frequently one's beliefs are changing accordingly services are determined.

\subsection{Nature of services}

Project specification consists services for the project personnel. The services may be person-driven, product-driven, and process-driven depending on the nature and type of project. For an instance, a civil construction project consists all three types of services. The project personnel have their own choices and preferences concerning their accommodation, entertainment, and socialization. The projects will have site offices, equipment, and machineries that need services of different types and categories. The construction project management is a process that is also passing through multiple processes like legal, social, religious, and cultural requirements at the project sites. The processes demand particular services of specific type. Projects being capable to meet the person, product, and process driven services are likely to be more efficient and effective when compared with the others that are failing to meet the service requirement.

The nature and type of services varies according to the persons' involvement in the project. The project personnel, freight forwarders, bankers, insurance agents, custom clearance agents, warehousing, government employees, pressure groups like child rights activists, environmentalists, and so on are demanding services differently. The services' demand heavily depends on the culture of the services recipients and services providers. The standardized services or specifications would not work in case of highly diversified cultural settings of the persons involved in the project. The construction projects in Nepal were not completed within the specified time and resource limits, instead had taken substantially longer time and higher financial resources delaying in its completion. The major reason behind the unnecessary delay and excess of resource was the project specifications and conditions relating to the person and commodity specific services (Bhattarai, 2006).

\subsection{Services composition}

People in project are not engaged only with their knowledge, skills, and experience but also they are engaged with their cultural preferences. The cultural configuration elements like eating, learning, mannering, and so on are influencing the composition services at the project. A well-written project specification needs to be 
compatible with the cultural settings at the project site. The concerns like who provides what type of services to whom in what way and when are critical in case of project management of international nature. The concerns are more severe while managing projects with international mobility of persons to and from the project site. The services vary concerning lodging, foods, health, insurance, entertainment, events, festivals and similar others from project to project. Depending on the type and mobility of persons, services composition takes the form of standardization, customization, and personalization.

\subsection{Role of cultural configuration}

International projects pay insufficient importance to culture or value system of the host society while writing project specifications. More specifically, people prefer services that best serve their individual culture preferences. It was found that sons or daughters of the same parents had preferred different types/category of services while meeting the same rituals. Individualized service better serves the needs of individuals than the customized or standardized services. Providing services with 'affection and compassion' have been considered only natural service, otherwise it becomes an artificial one. If not, there would be no difference between the service by artificial intelligence and natural intelligence. Who will serve better depends not only on the educational attainment, but also depends mostly on the culture in which s/he has grown up. Services provided only for material benefits are not considered best and worthwhile (Bhattarai, 2015). Services sector in international project management requires sufficient attention to the religious, business, government, political, vacations, and family purposes of the project team members and other associates. The accommodation, foods and beverages, entertainment, recreation, and similar other aspects of the people associated with the projects are directly concerned with the culture of the parties involved thereof.

\subsection{Services composition in international project management}

International project management is comparatively more diversified than national project management. It is argued that cultural boundary is more effective in bringing people together than the political boundary. Services are culture specific; therefore, political boundaries are less effective in international projects. The services part of international project specification depends on the cultural diversity and variation adaptability in particular firm, region, or nation. The degree of standardization, customization, and personalization depends on the levels of cultural diversity and service variation adoptability of the parties involved as shown in the figure mentioned herewith (Bhattarai, 2015).

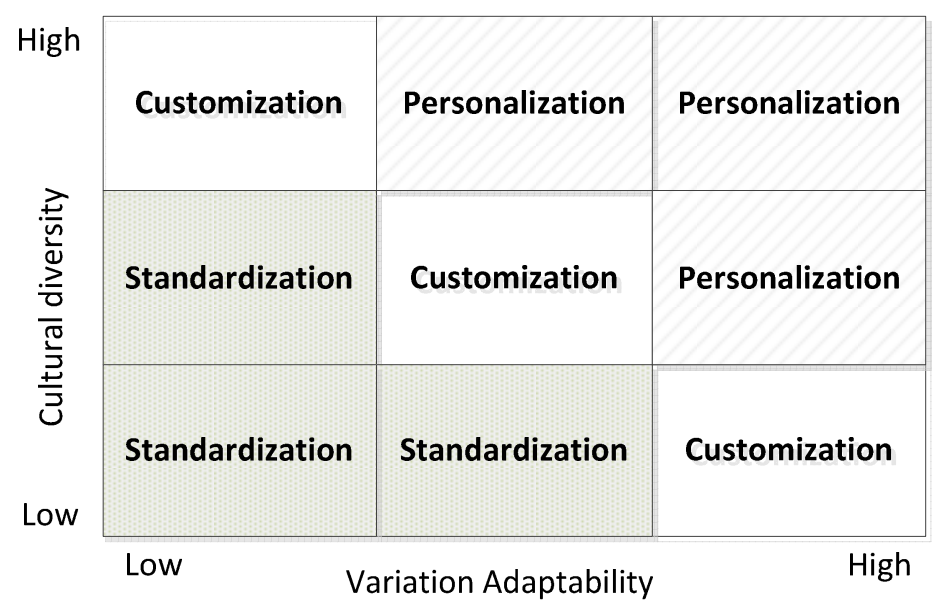

Figure 2. Model-free services alignment practice

Cultural diversity refers the dimensions and variation of the cultural configuration. Demands of the configuration differ significantly across the individuals and societies. It has been found that the elements of the cultural configuration were demanding varieties even among the individuals of the same culture. Individuals try 
to adopt the comfortable cultural value, which varies from person to person. Significance of an individual is based on his or her response to the diversified culture. Services variation adaptability differs from individual to individual. It is an ability of an individual to adopt the services that are compatible to his or her own culture and preference. The ability refers the financial, socio-political, and infrastructural ability of the individuals. The adoptive capacity differs significantly with the degree of comfortability from person to person and from project to project.

As mentioned in Figure 2, services standardization is the process of making items or activities of the same type, have the same features or qualities whereas personalization is the process of designing or changing something so that it is suitable to the choice of the person receiving the services. The process of customization attempts to categorize the services in order to make the requirements of certain community or class of people. The customization also refers the standardized customization and personalized customization. In both the cases, the person must be capable to adapt in all the ways- financially, socially, and psychologically (Bhattarai, 2015).

\subsection{General considerations}

Project planners conduct feasibility studies before preparing project specifications, but they do not test cultural compatibility. They may refer national culture and make considerations accordingly. However, this paper argues that there is no national culture as such but there is localized, communalized, and personalized culture. Cultural values cannot be assessed accurately by the outsiders who are not familiar with the language and culture of that particular locality, community, and personality.

The existing tendency of writing services component of international projects has not paid sufficient attention to the cultural configuration and its compatibility with the specifications. The practice of providing services to the person from developed countries who are engaged in the projects are not compatible with the configurations of the services provider and services recipient. However, the practices can be enhanced to increase the effectiveness of socio-economic development projects by giving sufficient attentions to the cultural configuration, diversity, and service variation adoptability. The programs initiated by the government and non-government organizations have launched a large number of developmental projects but only a few have been found little successful in their mission when the projects where able to maintain cultural congruency.

\section{Conclusion and implication}

As the person moves across the different parts of the globe in connection with development projects, s/he desires services and items of his or her requirements and choices. Identification of the individual's cultural configuration and responding accordingly will enhance effectiveness of international projects of socio-economic development. Comfortable Cultural Configuration (3Cs) is one secret of successful international projects. While looking at the Nepalese history of the last six decades, it was found that those developmental projects and programs were comparatively more successful and effective that were compatible with the cultural configuration, and those were less effective or failed in one way or the others that were incompatible with the cultural configuration. Contribution of this paper is an extension of the work of Bhattarai, 2015 and it finds the elements of cultural configuration. Bhattarai's service alignment practice was tested in the field of international project management practices. The test of verification provided additional insight that services alignment practice in project management should be made model-free. The implication of this paper directly concerns to the international project specification writing processes. It suggest project planners to consider cultural configuration as one of the determinants of project success and insists to ensure compatibility between the configuration and services composition while managing projects with international and cross-cultural mobility. 


\section{References}

Acharya, G. P., \& Bhattarai, R. K. (2012, January). Insights on issues of trade unions and industrial relations: A Perceptual survey of opinion leaders. Administration and Management Review, 24(1), 140-161.

Bhalla, P. P. (2005). Hindu rites, rituals, customs and traditions. Pustak Mahal: India.

Bhattarai, R. K. (2006). Project management: Nepalese experience. PRABAHA: Journal of Management, 16, 48-55.

Bhattarai, R. K. (2015). Infrastructure development in developing countries: issues of tourism, cultural configuration, and service alignment. In N. Ray, D. K. Das, S. Chaudhuri, \& A. Ghosh (Eds.), Strategic infrastructure development for economic growth and social change (pp. 92-119). Hershey, PA, USA: IGI Global. http://dx.doi.org/10.4018/978-1-4666-7470-7.ch008

Chong, J. K., \& Park, J. (2003). National culture and classical principles of planning. Cross Cultural Management: An International Journal, 10(1), 29-39. http://dx.doi.org/10.1108/13527600310797513

Johnson, G., Scholes, K., \& Whittington, R. (2009). Exploring corporate strategy (7th ed.). New Delhi: Pearson Education.

Sharma, B. (1963). Nepali culture. Kathmandu: Shajha Prakashan.

Sharma, J. L. (2001). Janak lal sharmaka prabandhaharu. Kathmandu: Bagar Foundation. 
Bhattarai, R. K. 